\title{
Ghrelin in patients with irritable bowel syndrome
}

\author{
M. EL-SALHY, E. LILLEB $\varnothing$, A. REINEMO and L. SALMELID \\ Section for Gastroenterology, Institute of Internal Medicine, \\ University of Bergen and Stord Helse-Fonna Hospital, Stord, Norway \\ Received November 26, 2008; Accepted January 21, 2009
}

DOI: 10.3892/ijmm_00000183

\begin{abstract}
General gastrointestinal dysmotility occurs in patients with irritable bowel syndrome (IBS). Ghrelin seems to play an important role in regulating gastrointestinal motility. The present study was undertaken, therefore, to establish the possible role of ghrelin in the pathophysiology of IBS. Thirty-seven patients with IBS (19 had IBS-constipation and 18 IBS-diarrhoea) were included in this study. Ten healthy volunteers served as controls. After overnight fast, blood samples were drawn from patients and controls, and a gastroduodenal endoscopy was performed. Biopsies were taken from oxyntic mucosa and duodenum. Ghrelin cell density was determined by computer image analysis after immunohistochemical staining of the tissues. Total and active ghrelin were detected in tissue extracts and plasma by commercially available RIA and ELISA Kits. The density of ghrelinimmunoreactive cells in the oxyntic mucosa was significantly lower in IBS-constipation and significantly higher in IBSdiarrhoea patients than healthy controls $(\mathrm{P}<0.0001$ and $<0.0001$, respectively). There was no statistical difference in total or active ghrelin between IBS patients and controls, regarding tissue extracts or plasma. In order to compensate for the increase and decrease in the ghrelin cell density, the synthesis and release of ghrelin may be decreased and increased in IBS-diarrhoea and IBS-constipation patients, respectively. It has been speculated that this compensatory mechanism may be subjected from time to time to fatigue with the subsequent increased and decreased synthesis and release of ghrelin in IBS-diarrhoea and IBS-constipation with a subsequent intermittent diarrhoea or constipation seen in these patients, respectively.
\end{abstract}

\section{Introduction}

Approximately 15 to $25 \%$ of the world population suffers from irritable bowel syndrome (IBS) (1). IBS is a chronic

Correspondence to: Professor Magdy El-Salhy, Section for Gastroenterology, Medicine Clinic, Stord Helse-Fonna Hospital, Box 4000, 5409 Stord, Norway

E-mail: magdy.el-salhy@helse-fonna.no

Key words: ghrelin, irritable bowel syndrome, immunocytochemistry, oxyntic mucosa, radioimmunoassay condition, which is characterized by abdominal discomfort or pain, abdominal bloating and changes in bowel habit $(1,2)$. The degree of symptoms varies in different patients from tolerable to severe, interfering with daily activity. IBS is the most common diagnosis in gastroenterology and is estimated to be $20-40 \%$ of all consultation performed by gastroenterologists $(2,3)$. Besides the increased morbidity caused by IBS, it represents an economic burden to the society in different indirect forms such as increased sick leave and over consumption of healthcare resources $(2,3)$. General disturbances in gastrointestinal motility have been reported in patients with IBS (4-10). The cause of gastrointestinal dysmotility has been speculated to be a result of genetic, psychosocial factors and stress (1-3).

Ghrelin is a 28 -amino acid peptide hormone, which was isolated from the stomach (11). Ghrelin originates mostly from endocrine cells in the oxyntic mucosa of the stomach but small amounts were found in both the small intestine and arcuated nucleus of the hypothalamus $(11,12)$. Ghrelin has several functions, the most known is its growth hormone $(\mathrm{GH})$-releasing effect in the pituitary, where it acts synergistically with GH-releasing hormone $(11,13)$. Ghrelin also increases appetite and feeding and plays a major role in energy metabolism $(14,15)$. Furthermore, ghrelin has been found to accelerate gastric as well as small and large intestinal motility (16-26).

As ghrelin seems to play an important role in regulating gastrointestinal motility and IBS patients exhibit gastrointestinal dysmotility, the present study was undertaken to establish the possible role of ghrelin in the pathophysiology of IBS.

\section{Materials and methods}

Patients and healthy subjects. Thirty-seven patients with irritable bowel syndrome (IBS) according to the Rome III criteria (35 females and 2 males; mean age 41 years; range 2260) were included in this study. These patients did not show any alarming symptoms. The patients were subdivided into 2 subtypes according to Rome III criteria. Thus, 19 patients had IBS-constipation (all females; mean age 38 years; range 24-57) and 18 patients with IBS-diarrhoea (16 females and 2 males; mean age 44 years; range 22-60). Ten healthy volunteers without any gastrointestinal complaints ( 8 females and 2 males; mean age 32 years; range 21-49) served as controls. The study was performed in accordance with the Declaration of Helsinki and was approved by the Local 
Committee for Medical Research Ethics. All subjects gave oral and written consent. After overnight fast, blood samples were drawn from patients and controls, and a gastroduodenal endoscopy was performed.

Gastrointestinal endoscopy. During the endoscopy procedure, 9 biopsies were taken from the corpus (major curvature) and pars decendens duodeni (distal to papilla of Vateri). In addition, biopsies were taken from the antrum and used in the CLO test for Helicobacter pylori.

Histopathology and immunohistochemistry. Three of the biopsies taken from the corpus and from the duodenum were fixed in $4 \%$ buffered paraformaldehyde overnight, embedded in paraffin and cut into $5-\mu \mathrm{m}$ sections. The sections were stained by haematoxylin and eosin and immunostained with the avidin-biotin-complex (ABC) method (Dako Cytomation, Glostrup, Denmark) as previously described in detail (27). The primary antiserum used was anti-ghrelin (polyclonal, code no. 00182, dilution 1:1600, Phoenix Pharmaceuticals, Belmont, CA, USA). The sections were counterstained slightly with haematoxylin. Negative controls included replacing the primary antiserum with $1 \%$ bovine albumin and by preincubating the diluted antiserum with excessive ghrelin $(50 \mu \mathrm{g} /$ $\mathrm{ml}$, NeoMPS, Strasbourg, France) at $4^{\circ} \mathrm{C}$ overnight.

Computerized image analysis. This was performed using Leica's Quantimet 600MC Image Processing and Analysis System (Leica, Cambridge, UK) linked to an Olympus microscope, type BX50. The program used in this system was QWIN, Leica's Windows Based Image Analysis Tool Kit, version 2.6. The system included QUIPS (version 2.6), which is an interactive programming system. When using x20 objectives, each pixel in the computer monitor corresponds to $0.173 \mu \mathrm{m}$ and the frame (fields) representing an area of $5436 \mu \mathrm{m}^{2}$. The number of ghrelin-immunoreactive cells and the area of the epithelial cells were measured. Using QUIPS, an automated standard sequence analysis operation was created, as described previously in detail (28). Briefly, the number of immunoreactive cells was counted using the field measurements. The areas of the epithelial cells were measured using a threshold setting. Data from each field were tabulated, the number of cells $/ \mathrm{mm}^{3}$ were computed and statistically analysed automatically. Measurements were carried out in 10 randomly chosen fields in the stomach and duodenum of each individual. The $\mathrm{x} 20$ objective was used.

Detection of ghrelin. The blood samples were collected in pre-chilled polypropylene tubes containing EDTA $(1 \mathrm{mg} / \mathrm{ml}$ blood) and aprotinin ( $500 \mathrm{U} / \mathrm{ml}$ blood) and were then immediately centrifuged at $4^{\circ} \mathrm{C}$ for $10 \mathrm{~min}$ at $3000 \mathrm{rpm}$. The plasma fraction was collected and diluted $1 / 10$ volume with $1 \mathrm{~N} \mathrm{HCl}$ and stored at $-20^{\circ} \mathrm{C}$ until analysis. The mean weight of the biopsies obtained from the gastric corpus was $67.7 \mathrm{mg}$ (range 102.6-36.6) and from the duodenum, $64 \mathrm{mg}$ (range 96.8-30.6). The tissue from the stomach and duodenum were quickly frozen and stored at $-80^{\circ} \mathrm{C}$ until the time of extraction. Each tissue sample was diced and boiled for $10 \mathrm{~min}$ in $2 \mathrm{ml}$ distilled water to inactivate intrinsic proteases. The solution was adjusted to $1 \mathrm{M}$ acetic acid after cooling, and the tissue
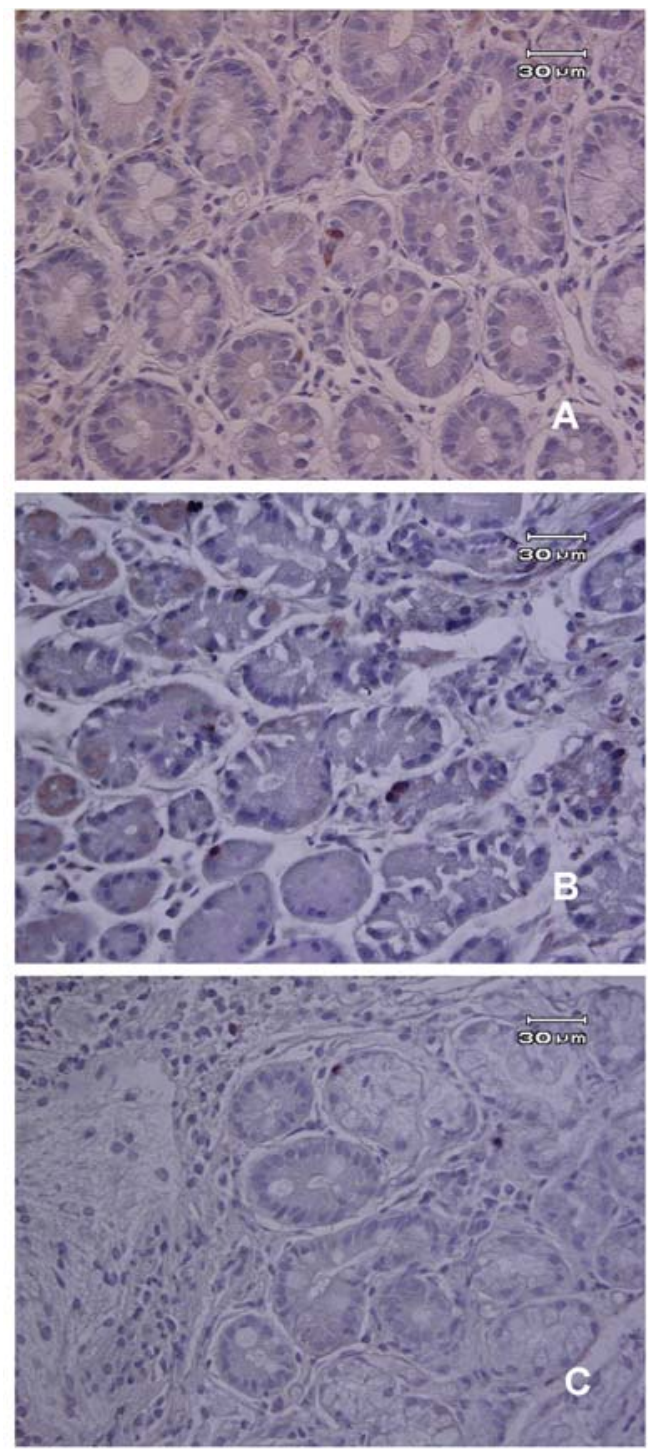

Figure 1. Ghrelin-immunoreactive cells in the oxyntic mucosa of a control (A), a patient with IBS-diarrhoea (B) and a patient with IBS-constipation (C).

was homogenized with a Polytron mixer. The supernatant was obtained after centrifugation at $10,000 \mathrm{rpm}$ for $30 \mathrm{~min}$, and then stored at $-80^{\circ} \mathrm{C}$ until the time of analysis.

Total ghrelin (acylated and des-acylated) was measured with a commercially available Radioimmunoassay (RIA) Kit (Phoenix Pharmaceuticals, Inc.). The active (acylated) ghrelin was detected by a commercially available ELISA Kit (Sceti Co., Ltd., Tokyo, Japan).

Statistical analysis. The Kruskal-Wallis non-parametric ANOVA test and Dunn's post-test were used to compare controls and the 2 subgroups of IBS patients. P-values $<0.05$ were considered significant.

\section{Results}

Gastrointestinal endoscopy. The stomach and duodenum of both patients and the healthy volunteers were macroscopically normal. Three patients and one healthy volunteer exhibited a positive CLO test, indicating infection with $H$. pylori. 


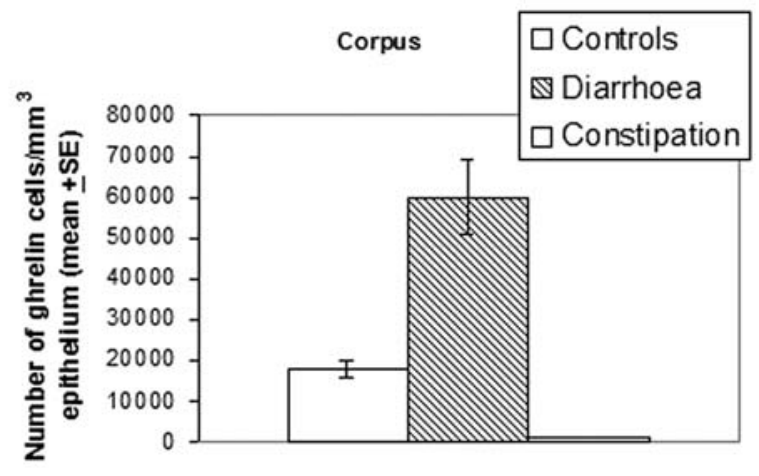

Figure 2. Density of ghrelin-immunoreactive cells in the oxyntic mucosa of the stomach in healthy subjects and in patients with IBS. ${ }^{* * *} \mathrm{P}>0.0001$.

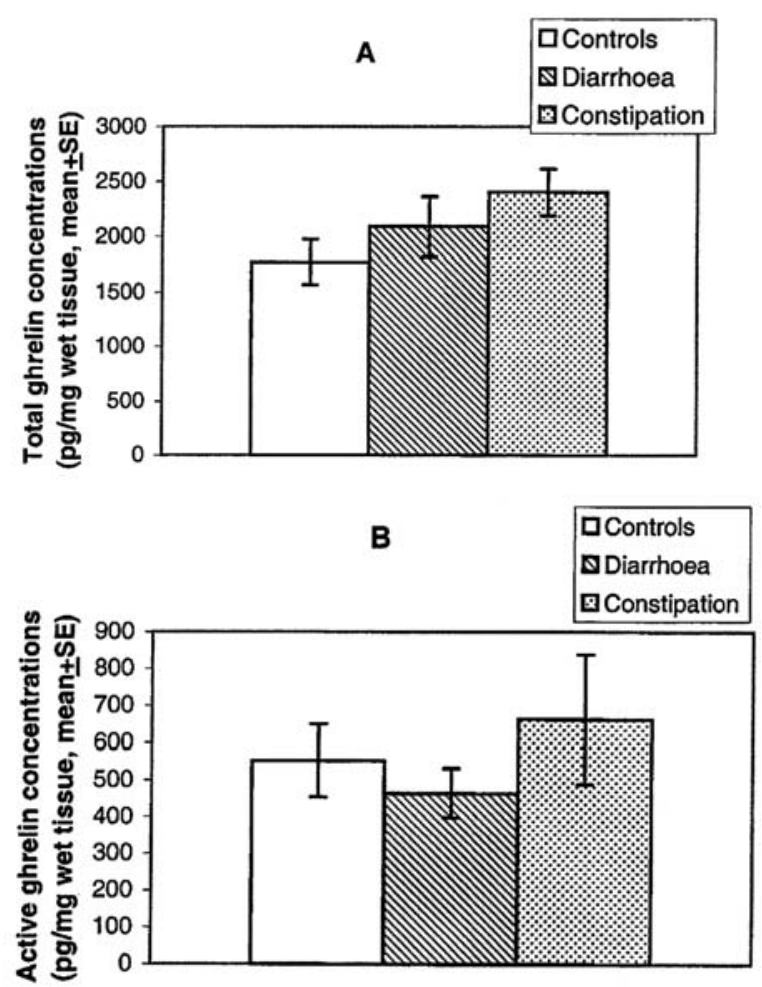

Figure 3. Concentrations of total (A) and active (B) ghrelin in tissue extracts from the oxyntic mucosa of controls and patients.

Histopathology and immunohistochemistry. Histopathological examination of the gastric and duodenal biopsies from patients and the healthy volunteers revealed normal histology. Ghrelinimmunoreactive cells were found in the stomach oxyntic mucosa and among the epithelial cells of the duodenum. In the duodenum, ghrelin cells were few and unevenly distributed which did not allow any reliable quantification. They occurred mostly in the crypts. Ghrelin cells were round, flask-shaped or triangular (Fig. 1).

Computerized image analysis. The density of ghrelinimmunoreactive cells in the oxyntic mucosa of patients with IBS-diarrhoea was significantly higher $(\mathrm{P}<0.0001)$ and this density in patients with IBS-constipation was significantly lower than healthy controls $(\mathrm{P}<0.0001)$ (Fig. 2).

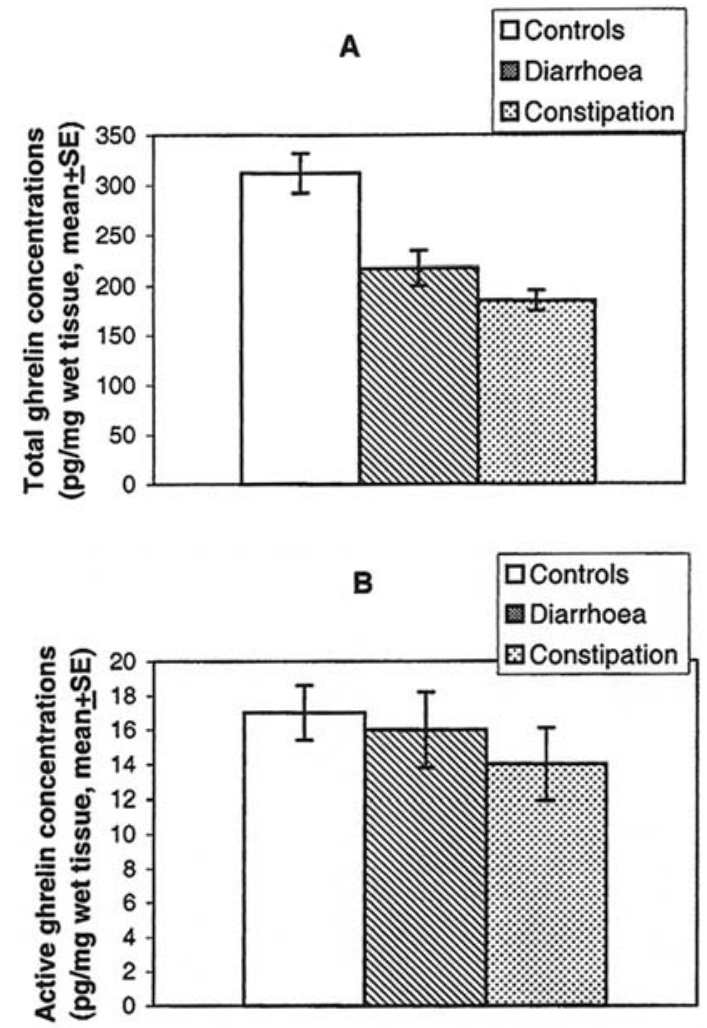

Figure 4. Concentrations of total (A) and active (B) ghrelin in tissue extracts from the duodenal mucosa of controls and patients.

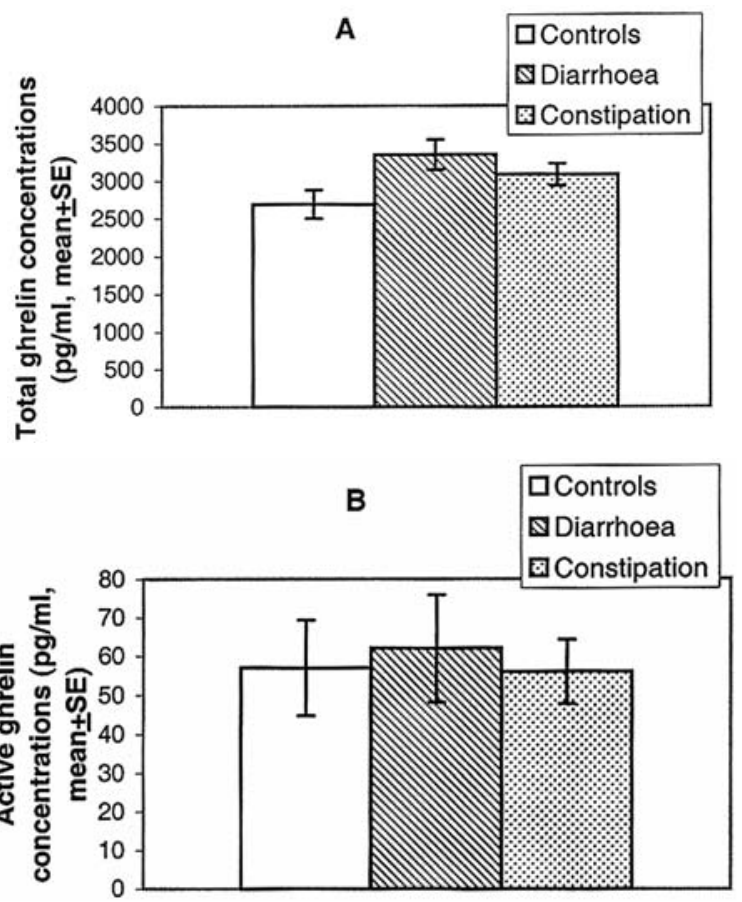

Figure 5. Plasma concentrations of total (A) and active (B) ghrelin in controls and patients.

Detection of ghrelin. There was no statistical difference between controls and patients regarding the concentrations of total and active ghrelin in the corpus, duodenum and plasma (Figs. 3-5). 


\section{Discussion}

In the present study, ghrelin was found to be affected in patients with IBS. Ghrelin has been reported to be abnormal in other gastrointestinal diseases such as inflammatory bowel diseases (29), coeliac disease (30-33) and atrophic gastritis (34-36). Thus, ghrelin seems to be involved in the pathophysiology of gastrointestinal diseases/disorders.

The present study showed that ghrelin cell density in the oxyntic mucosa of patients with IBS was abnormal. The nature of this abnormality was, however, different in the different subtypes of IBS. Thus, whereas ghrelin cell density increased in IBS-diarrhoea patients, it was reduced in IBSconstipation patients. The concentrations of total and active ghrelin in extracts of the oxyntic mucosa and of the duodenum of IBS patients did not differ from those of healthy controls. There was no difference either in the plasma levels of total and active ghrelin between IBS patients and controls. It is conceivable, therefore, to conclude that in order to compensate for the increase and decrease in the ghrelin cell density, the synthesis and release of ghrelin decreased and increased in IBS-diarrhoea and IBS-constipation patients, respectively.

One may speculate further, that this compensatory mechanism in IBS patients may be subjected to fatigue from time to time with the subsequent increased and decreased synthesis and release of ghrelin in IBS-diarrhoea and IBSconstipation, respectively. As ghrelin accelerates gastrointestinal motility (16-26), that would account for the intermittent diarrhoea and constipation noted in these patients, respectively.

The present findings in the oxyntic mucosa of increased ghrelin cell density in IBS-diarrhoea and the paucity of ghrelin cells in IBS-constipation patients raise the question: whether ghrelin antagonist and ghrelin would have a therapeutic role in these patients.

\section{Acknowledgements}

This study was supported by grants from Hesle-Fonna. This study was presented in abstract form at the 13th World Congress on Advances in Oncology and 11th International Symposium on Molecular Medicine, Hersonissos, Crete, Greece, October 9-11, 2008.

\section{References}

1. Thompson WG: A world view of IBS. In: Irritable Bowel Syndrome: Diagnosis and Treatment. Camilleri M and Spiller R (eds). Saunders Co., Philadelphia and London, pp17-26, 2002.

2. Everhart JE and Renault PF: Irritable bowel syndrome in officebased practice in the United States. Gastroenterology 100: 998-1005, 1991.

3. Harvey RF, Salih SY and Read AE: Organic and functional disorders in 2000 gastroenterology outpatients. Lancet 1: 632-634, 1983.

4. Whorwell PJ, Clouter C and Smith CL: Oesophagus motility in the irritable bowel syndrome. Br Med J 282: 1101-1102, 1981.

5. Caballero-Plasencia AM, Valenzula-Barranco M, HerreriasGutierrez JM and Esteban-Carretero JM: Altered gastric emptying in patients with irritable bowel syndrome. Eur J Nucl Med 26: 404-409, 1999.

6. Evans PR, Bak YT, Shuter B, Holsch R and Kellow J: Gastroparesis and small bowel dysmotility in irritable bowel syndrome. Dig Dis Sci 42: 2087-2093, 1997.
7. Van Wijk HJ, Smout AJ, Akkerman LM, Roelofs JM and ten Thije OJ: Gastric emptying and dyspeptic symptoms in irritable bowel syndrome. Scand J Gastroenterol 27: 99-102, 1992.

8. Cann PA, Read NW, Brown C, et al: Irritable bowel syndrome: relation of disorders in the transit of a single solid meal to symptom patterns. Gut 24: 405-411, 1983.

9. Kellow JE and Philips SF: Altered small bowel motility in irritable bowel syndrome is correlated with symptoms. Gastroenterology 92: 1885-1893, 1987.

10. Kellow JE, Philips SF, Miller LJ, Zinsmeister AR and Charboneau JW: Dysmotility of the small bowel in irritable bowel syndrome. Gut 29: 1236-1243, 1988.

11. Kojima M, Hosoda H, Date J, Nakazato M, Matsuo H and Kangawa K: Ghrelin is growth-hormone-releasing acetylated peptide from stomach. Nature 402: 656-660, 1999.

12. Date Y, Kojima M, Hosoda H, Sawaguchi A, Mondal MS, Suganuma T, Matsukura S, Kangawa K and Nakazato M: Ghrelin, a novel growth hormone-releasing acetylated peptide, is synthesized in a distinct endocrine cell type in the gastrointestinal tracts of rats and humans. Endocrinology 141: 4255-4261, 2000.

13. Hataya Y, Akamizu T, Takaya K, Ariyasu N, Sajjo M, Moriyama K, Shimatsu A, Kojima M, Kangawa K and Nakao K: A low dose of ghrelin stimulates growth hormone $(\mathrm{GH})$ release synergistically with GH-releasing hormone in humans. J Clin Endocrinol Metab 86: 4552, 2001.

14. Wren AM, Seal LJ, Cohen MA, Brynes A, Frost GS, Murphy KG, Dhillo LO, Ghatei MA and Bloom SR: Ghrelin enhances appetite and increases food intake in humans. J Clin Endocrinol Metab 86: 5992, 2001.

15. Hosoda H, Kojima $M$ and Kangawa K: Ghrelin and the regulation of food intake and energy balance. Mol Interv 8: 494-503, 2002.

16. Masuda Y, Tanaka T, Inomata N, Ohmura N, Tanaka S and Itoh Z: Ghrelin stimulates gastric acid secretion and motility in rats. Biochem Biophys Res Commun 276: 905-908, 2000.

17. Fujino K, Inui A, Asakawa A, Kihara N, Fujimura M and Fujimiya M: Ghrelin induces fasted motor activity of the gastrointestinal tract in conscious fed rats. J Physiol 550: 227-240, 2003.

18. Dornonville de la Cour C, Lindström E, Norén P and Håkansson R: Ghrelin stimulates gastric emptying but without effect on acid secretion and gastric endocrine cells. Regul Pep 120: 23-32, 2004.

19. Fukuda H, Mizuta Y, Isomoto H, Takeshima F, Ohnita K and Ohba K: Ghrelin enhances gastric motility through direct stimulation of intrinsic neural pathway and capsaicin-sensitive afferent neurones in rats. Scand J Gastroenterol 39: 1209-1214, 2004.

20. Levin F, Edholm T, Schmidt PT, Grybäck P, Jacobsson H and Dergerblad M: Ghrelin stimulates gastric emptying and hunger in normal weight humans. J Clin Endocrinol Metab 91: 3279-3280, 2006.

21. Tack J, Deportere I, Bischops R, Delporte C, Coulie B and Meulemans A: Influence of ghrelin on interdigestive gastrointestinal motility in humans. Gut 55: 327-333, 2006.

22. Ariga H, Tsukamoto K, Chen C, Mantyh C, Pappas TN and Takahashi T: Endogenus acyl ghrelin is involved in mediating spontaneous phase III-like contractions in the rat stomach. Neurogastroenterol Motil 19: 675-680, 2007.

23. Ariga H, Nakade Y, Tsukamoto K, Imai K, Mantyh C, Pappas TN and Takahashi T: Ghrelin accelerates gastric emptying via an early manifestation of antro-pyloric coordination in conscious rats. Regul Pep 146: 112-116, 2008.

24. Tümer C, Oflazoglu HD, Obay BD, Kelle M and Tasdemir E: Effects of ghrelin on gastric myoelectrical activity and gastric emptying in rats. Regul Pep 146: 26-32, 2008.

25. Edholm T, Levin F, Hellerström PM and Schmidt PT: Ghrelin stimulates motility in the small intestine of rats. Regul Pep 121: 25-30, 2004.

26. Tabbe JJ, Mornga S, Tebbe CG, Oertmann E, Arnold R and Schäfer K: Ghrelin-induced stimulation of colonic propulsion is dependent on hypothalamic neuropeptides Y1- and corticotrophin-releasing factor 1 receptor activation. J Neuroendocrinol 17: 570-576, 2005

27. El-Salhy M, Stenling R and Grimelius L: Peptidergic innervation and endocrine cells in the human liver. Scand J Gastroenterol 28: 809-815, 1993 .

28. El-Salhy M, Sandström O, Näsström E, Mustajbasic M and Zachrisson S: Application of computer image analysis in endocrine cell quantification. Histochem J 29: 249-255, 1997. 
29. Kamiris K, Koutroubakis IE, Xidakis C, Polychronaki M, Voudouri $\mathrm{T}$ and Kouroumalis EA: Circulating levels of leptin, adiponectin, resistin and ghrelin in inflammatory bowel disease. Inflamm Bowel Dis 12: 100-105, 2006.

30. Peracchi M, Conte D, Terrain C, Pizzinelli S, Gebbia C, Cappiello V, Spada A and Bardella MT: Circulating ghrelin levels in celiac patients. Am J Gastroenterol 98: 2474-2478, 2003.

31. Capristo E, Farnetti S, Mingrone G, Certo M, Greco AV, Addolorato $\mathrm{G}$ and Gasbarrini G: Reduced plasma ghrelin concentration in celiac disease after gluten-free diet treatment. Scand J Gastroenterol 40: 430-436, 2005.

32. Selimoglu MA, Altinkaynak S, Ertekin V and Akcay F: Serum ghrelin levels in children with celiac disease. J Clin Gastroenterol 40: 191-194, 2006.

33. Lanzini A, Magni P, Petroni M-L, Motta M, Lanazarotto F, Villanacci V, Amato M, Mora A, Bertolazzi S, Benini F and Ricci C: Circulating ghrelin level is increased in coeliac disease as in functional dyspepsia and reverts to normal during glutenfree diet. Aliment Pharmacol Ther 23: 907-913, 2006.
34. Checchi S, Montanaro A, Pasqui L, Ciuoli C, Cevenini G, Sestini F, Fioravanti C and Pacini F: Serum ghrelin as a marker of atrophic body gastritis in patient with parietal cell antibodies. J Clin Endocrinol Metab 92: 4346-4351, 2007.

35. Campana D, Nori F, Pagotto U, De Lasio R, Morselli-Labate AM Pasquali R, Corinaldesi R and Tomassetti P: Plasma acylated ghrelin levels are higher in patients with chronic atrophic gastritis. Clin Endocrinol 67: 761-766, 2007.

36. Alnoso N, Granada ML, Salinas I, Reverter JL, Flores L, Ojanguren I, Martinz-Càcerees EM and Sanmarit A: Plasma ghrelin in type 1 diabetic patients with autoimmune atrophic gastritis. Eur J Endocrinol 157: 763-769, 2007. 